\title{
The Inhibition Effect of Sodium Glutarate towards Carbon Steel Corrosion in Neutral Aqueous Solutions
}

\author{
G. Chan-Rosado and M. A. Pech-Canul \\ Departamento de Física Aplicada, Cinvestav-Mérida, Km. 6 Ant. Carr. a Progreso, AP73, Cordemex, 97310 Mérida, YUC, Mexico \\ Correspondence should be addressed to M. A. Pech-Canul; maximo.pech@cinvestav.mx
}

Received 31 August 2016; Revised 18 November 2016; Accepted 4 December 2016

Academic Editor: Yu Zuo

Copyright (C) 2016 G. Chan-Rosado and M. A. Pech-Canul. This is an open access article distributed under the Creative Commons Attribution License, which permits unrestricted use, distribution, and reproduction in any medium, provided the original work is properly cited.

\begin{abstract}
The inhibition effect of sodium glutarate towards corrosion of carbon steel in neutral $0.02 \mathrm{M} \mathrm{NaCl}$ solution was investigated with potentiodynamic polarization and electrochemical impedance measurements. Results of electrochemical measurements revealed a poor inhibitive action for low concentrations $(1 \mathrm{mM}$ and $5 \mathrm{mM})$ and a significant improvement in efficiency for concentrations of $32 \mathrm{mM}$ or higher. The protective film exhibited excellent stability in the temperature range $22^{\circ} \mathrm{C}-55^{\circ} \mathrm{C}$. Full chemical passivation was accomplished and analysis of the impedance spectra for the high concentrations of glutarate was consistent with the inhibition mechanism which assumes that the carboxylates support the passivation of carbon steel in aerated solutions by plugging the defect sites and that the passivation process is enhanced by adsorption of the carboxylates on the oxide-covered surface. Such mechanism was confirmed by the XPS analysis.
\end{abstract}

\section{Introduction}

The corrosion of carbon steel in neutral or slightly alkaline oxygen-containing solutions is a common problem in cooling water systems and an effective way to control the corrosion of steel is the addition of corrosion inhibitors [1]. Although several compounds have been reported to act as good corrosion inhibitors for steel in neutral media (e.g., molybdates, tungstates, polyphosphate, and phosphonate) [1-5], the use of carboxylic acid derivatives has been attractive since they are environmentally friendly and can be derived from fatty acids extracted from vegetable oils $[6,7]$.

The sodium salt of benzoic acid $\left(\mathrm{C}_{6} \mathrm{H}_{5} \mathrm{COONa}\right)$ is the classic carboxylic acid inhibitor used since the 1960s for protection of steel in neutral solutions [8-10]. Straight chain aliphatic carboxylates have also been reported by various authors as effective inhibitors. Mrowczynski and SzklaeskaSmialowska [11] reported the electrochemical behavior of iron in sulphate solutions in the presence of monocarboxylic acids with 6-10 carbon atoms in the molecule, showing that efficiency increases with increasing length of the hydrocarbon chain, provided that the concentration exceeds a critical value; they attributed the reduction in corrosion rate of iron to a synergistic action of these acids and dissolved oxygen. Reinhard and Rammelt [12-14] also investigated the passivation effect of some carboxylates, including straight chain mono- and dicarboxylates; they reported that dissolved oxygen forms a passive oxide film on iron and steel in the presence of the carboxylate above a critical minimum concentration. Hefter et al. [15] made a systematic study of the abilities of straight chain monocarboxylic $\left(\mathrm{C}_{n} \mathrm{H}_{2 n+1} \mathrm{COO}^{-}\right)$ and dicarboxylic $\left({ }^{-} \mathrm{OOC}\left[\mathrm{CH}_{2}\right]_{n} \mathrm{COO}^{-}\right)$acids to inhibit the corrosion of mild steel, copper, and aluminum in neutral solutions. For mild steel, short chain length $(n \leq 5)$ monocarboxylates were found to behave as either corrosive ( $n=0$ ) or weak inhibitors; from $n=6$ to $n=10$, the efficiency increased rapidly but decreased abruptly at $n=11$ and declined further up to $n=17$. In the case of dicarboxylates, they also observed that short chain lengths $(n \leq 3)$ were either corrosive $(n=0)$ or weak inhibitive; also, the inhibitor effectiveness increased from $n=4$ up to $n=12$ and decreased sharply at $n=14$. More recently, Lahem et al. [16] used electrochemical methods to investigate the efficiency of some dicarboxylates $(n=1,2,4$, and 8$)$ as inhibitors for mild steel in neutral chloride solutions. Their results showed that dicarboxylates with $n \geq 4$ have good 
efficiency (better efficiency with increasing carbon chain length) and behave predominantly as anodic inhibitors. The proposed mechanism of inhibition involves the formation of an insoluble ferric compound (iron dicarboxylate complex) on the metal surface after an initial oxidation of iron into ferrous ions. In recent works, Rajendran et al. have shown that the inhibitive effect of succinic and adipic acid $(n=2$ and 4 , resp.) can be enhanced by addition of $\mathrm{Zn}^{2+}$ ions, due to a synergistic action $[17,18]$. With FTIR, they determined that the protective film consists of a complex of the dicarboxylic acid with $\mathrm{Zn}^{2+}$ ions and $\mathrm{Zn}(\mathrm{OH})_{2}$.

In the study reported by Hefter et al. [15], modest inhibition efficiencies were observed for dicarboxylates with chain lengths of $n=2$ and $n=3$. However, such result corresponds to a fixed concentration of $5 \mathrm{mM}$. It is worth investigating how the protectivity can be improved by increasing the concentration.

In this work, a dicarboxylate with $n=3$ was chosen with the aim of providing further information with respect to that reported in the previous literature. The inhibitive effect of sodium glutarate $\left(\mathrm{NaOOC}\left(\mathrm{CH}_{2}\right)_{3} \mathrm{COONa}\right)$ on the corrosion of carbon steel in a near-neutral $0.02 \mathrm{M} \mathrm{NaCl}$ solution was investigated at ambient temperature for a range of concentrations $(1 \mathrm{mM}-100 \mathrm{mM})$ by potentiodynamic polarization and electrochemical impedance spectroscopy (EIS) measurements. The effect of temperature was investigated for the highest concentration. In addition, X-ray photoelectron spectroscopy (XPS) was used to analyze the composition of the protective layer. From these results, the corrosion inhibition mechanism was discussed.

\section{Experimental}

2.1. Materials. All experiments were carried out in a threeelectrode electrochemical cell with a platinum foil as counter electrode and an $\mathrm{Ag} / \mathrm{AgCl}$ reference electrode. The working electrode was made from a 1018 carbon steel rod embedded in epoxy resin, leaving an exposed area of $1 \mathrm{~cm}^{2}$. The chemical composition of this material was Fe-98.703\%, C-0.177\%, Mn$0.636 \%$, Cu-0.197\%, Si-0.0578\%, P-0.041\%, and traces of Ni, $\mathrm{Cr}, \mathrm{Mo}, \mathrm{Al}, \mathrm{S}$, and $\mathrm{Nb}$. Prior to each measurement, the working surface was abraded with $\mathrm{SiC}$ papers up to 600 grits, rinsed with distilled water and dried with a stream of hot air. The sodium glutarate solutions were prepared through neutralization of glutaric acid (obtained from Sigma-Aldrich ${ }^{\circledR}$ ) by sodium hydroxide in distilled water. For the first set of experiments, at ambient temperature $\left(22^{\circ} \mathrm{C}\right)$, solutions were prepared in a concentration range of $0.001 \mathrm{M}$ to $0.1 \mathrm{M}$. The effect of temperature on inhibition efficiency was investigated for the $0.1 \mathrm{M}$ glutarate solution conducting experiments at 3 other temperatures $\left(35^{\circ} \mathrm{C}, 45^{\circ} \mathrm{C}\right.$, and $\left.55^{\circ} \mathrm{C}\right)$ using a water bath temperature-controlled. The corrosive medium was a $0.02 \mathrm{M}$ $\mathrm{NaCl}$ solution, $\mathrm{pH}$ 7.4. Prior to each test, the solutions were preaerated by air bubbling during $15 \mathrm{~min}$.

2.2. Electrochemical Measurements. The electrochemical measurements were performed with a Gamry series G300 potentiostat-galvanostat. The working electrode was allowed

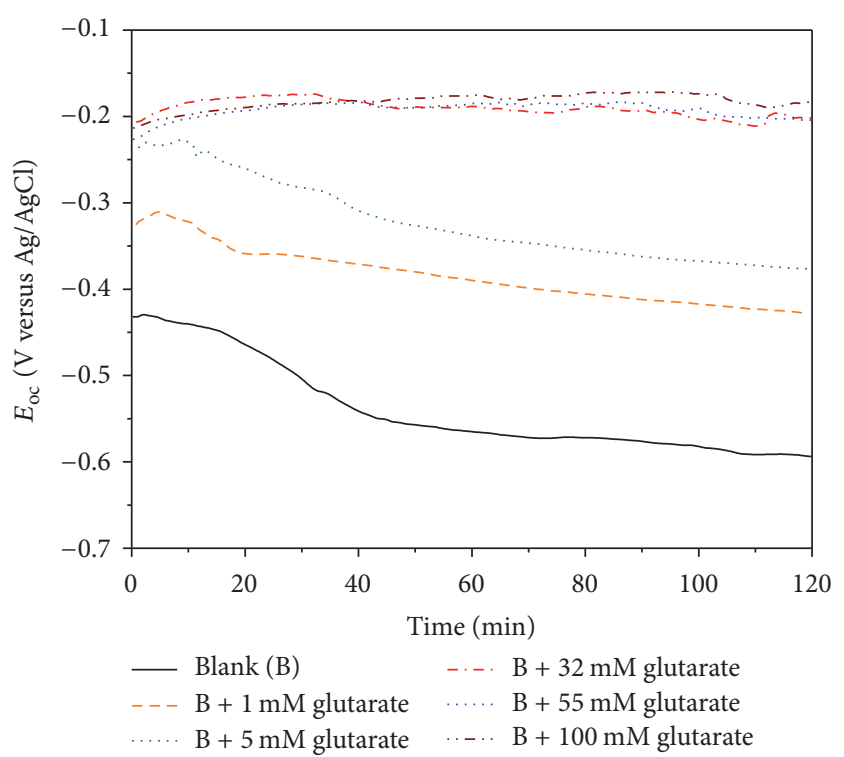

FIGURE 1: Variation with time of open circuit potential for carbon steel in air saturated $0.02 \mathrm{M} \mathrm{NaCl}$ solutions without and with additions of sodium glutarate.

to stabilize at open circuit conditions in the solution during 2 hours; then, EIS measurements were performed under potentiostatic conditions at the open circuit potential $\left(E_{\mathrm{oc}}\right)$ using a sine wave of $10 \mathrm{mV}$ amplitude in the frequency range from $10 \mathrm{KHz}$ to $10 \mathrm{mHz}$ with 5 points/decade. At the end, a potentiodynamic curve was recorded with a sweep rate of $1 \mathrm{mV} \mathrm{s}^{-1}$ in the range of $\pm 300 \mathrm{mV}$ versus $E_{\mathrm{oc}}$.

2.3. XPS Analysis. X-ray photoelectron spectroscopy (XPS) was used to analyze the chemical composition of the protective layer formed on the surface of carbon steel after $2 \mathrm{~h}$ immersion in the $\mathrm{NaCl}$ solution containing $0.1 \mathrm{M}$ of sodium glutarate. As a comparison, the analysis was also carried out for a reference sample of carbon steel not immersed in the solutions (covered with native oxide film). XPS measurements were carried out on a Thermo Scientific K-Alpha XPS spectrophotometer. A monochromatic Al K $\alpha$ X-ray source was used, with a spot area of $400 \mu \mathrm{m}$. High resolution core level spectra for Fe 2p, C 1s, and $\mathrm{O}$ 1s were acquired in the angle-resolved mode. Results are presented for two takeoff angles, $0^{\circ}$ and $50^{\circ}$, with respect to the normal.

\section{Results and Discussion}

3.1. Effect of Inhibitor Concentration at Ambient Temperature. Figure 1 shows the evolution with time of the open circuit potential for carbon steel in the $0.02 \mathrm{M} \mathrm{NaCl}$ solution without and with additions of sodium glutarate at different concentrations. In the blank solution, $E_{\text {oc }}$ starts at about $-430 \mathrm{mV}$ and gradually shifts towards more negative values reaching a value of $-590 \mathrm{mV}(\mathrm{Ag} / \mathrm{AgCl})$ after the $2 \mathrm{~h}$ immersion. This open circuit potential decay can be ascribed to breakdown of the air-formed oxide film. Such process was studied in 


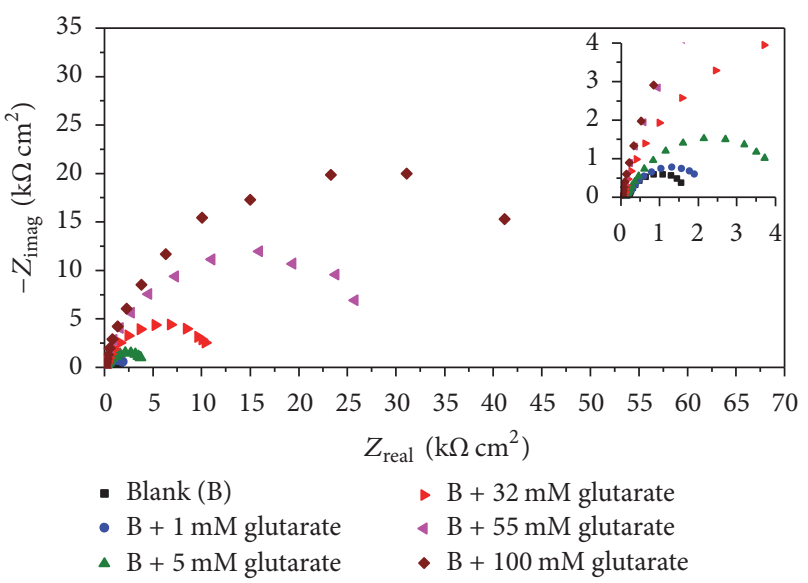

Figure 2: Typical Nyquist diagrams for carbon steel in the $0.02 \mathrm{M}$ $\mathrm{NaCl}$ solution without (blank) and with additions of sodium glutarate.

detail by Gilroy and Mayne [19] and Konno et al. [20] for airformed oxide films on iron. Both research groups carried out open circuit potential measurements in corrosive solutions and observed that, due to dissolution of the oxide film, $E_{\mathrm{oc}}$ initially decreases gradually with immersion time and then it drops rapidly to $-0.76 \mathrm{~V}(\mathrm{Ag} / \mathrm{AgCl})$, the free corrosion potential of Fe. We did not observe the sudden decrease to $-0.76 \mathrm{~V}$; so it appears that during the $2 \mathrm{~h}$ immersion the air-formed oxide film is not completely removed yet. The addition of sodium glutarate leads to a positive shift in the initial value of $E_{\text {oc }}$. However, for the two lowest concentrations ( $1 \mathrm{mM}$ and $5 \mathrm{mM}$ ), the potential stabilized in the region around $-400 \mathrm{mV}$, suggesting that sodium glutarate assisted in repairing defects of the air-formed oxide film but not enough to ensure full protection. For glutarate concentrations $\geq 32 \mathrm{mM}$, the initial $E_{\mathrm{oc}}$ was $\sim-225 \mathrm{mV}(\mathrm{Ag} / \mathrm{AgCl})$ and remained around $-200 \mathrm{mV}$ throughout the immersion period. This ennoblement of potential in the presence of oxygen and of the nonoxidizing inhibitor anion has been ascribed in the early literature to a passivation process [21, 22]. As discussed by Brasher [22], the anion adsorbs on the metal surface at formation. Rammelt et al. $[12,14]$ observed this passivating effect for mild steel with carboxylates and suggested that the protective film consists mainly of Fe(III) oxide with inclusion of insoluble $\mathrm{Fe}(\mathrm{III})$ carboxylate. So, the results in Figure 1 suggest that solutions containing sodium glutarate with a concentration of $32 \mathrm{mM}$ or higher provide much better conditions for a satisfactory inhibition compared to the solutions with lower concentration of glutarate (1 and $5 \mathrm{mM}$ ).

The typical impedance responses obtained for the carbon steel electrode after $2 \mathrm{~h}$ immersion in solutions with and without inhibitor are presented as complex plane plots in Figure 2. The inset shows a zoom in of the region $0-4 \mathrm{k} \Omega \cdot \mathrm{cm}^{2}$ (in the $x$-and $y$-axis) to help visualize the spectra with lower impedance amplitude (i.e., for steel in the blank and solutions with $1 \mathrm{mM}$ and $5 \mathrm{mM}$ of sodium glutarate).
Although the impedance diagrams apparently look like a slightly depressed single capacitive semicircle, the Bode plot and the equivalent circuit analysis (see below) suggest that in all cases the Nyquist diagram actually consists of two, closely overlapped, time constants.

As indicated above, the carbon steel surface in the blank solution was initially covered with an air-formed oxide film which undergoes breakdown with increasing immersion time; when carboxylate is added to the chloride solution, it acts at local defects of the thin oxide layer sealing them according to the pore plugging concept [23]. Nevertheless, for low concentrations of glutarate $(1 \mathrm{mM}$ and $5 \mathrm{mM})$, full passivation could not be achieved. Thus, the impedance data obtained in the blank and the solutions with the two lowest additions of glutarate can be modeled with the equivalent circuit for an imperfectly covered electrode (Figure 3(a)) where $R_{s}$ is the solution resistance, $R_{f}$ and $C_{f}$ correspond to the resistance and capacitance relative to the surface film, and $C_{\text {int }}$ is the interfacial capacitance in parallel with $R_{p}$ the polarization resistance, at the defect sites (where charge transfer takes place).

On the other hand, the $E_{\mathrm{oc}}$ values in Figure 1 give an indication that in solutions containing $32 \mathrm{mM}$ or higher of sodium glutarate the carbon steel electrode is in a passive state. As discussed previously in related literature $[13,14,22]$, the passivation process is enhanced by adsorption of the carboxylates on the oxide-covered surface. Accordingly, the impedance data obtained in solutions with sodium glutarate in concentrations $\geq 32 \mathrm{mM}$ were modeled with the equivalent circuit (Figure 3(b)) for a two-layer system, with an oxide layer on the metal surface and an adsorption layer on it [13]; $R_{s}$ is the solution resistance, $R_{\mathrm{ads}}$ and $C_{\mathrm{ads}}$ correspond to the resistance and capacitance of adsorption of an electrochemically indifferent species; $C_{\mathrm{ox}}$ and $R_{\mathrm{ox}}$ are the capacitance and resistance associated with the oxide layer.

Bode plots comparing experimental versus fitted data for carbon steel in $0.02 \mathrm{M} \mathrm{NaCl}$ solutions with different concentrations of sodium glutarate are presented in Figures 4 and 5. Very good fits to the experimental impedance spectra were obtained with the two equivalent circuit models in Figure 3. The optimum fit parameters are presented in Tables 1 and 2. As usual, for the fitting process, a constant phase element (CPE) is introduced to account for nonideal capacitive behavior due to surface inhomogeneity [24, 25]. Its admittance is given by $Y_{\mathrm{CPE}}=Y_{0}(j \omega)^{\alpha}$, where $\omega$ is the sine wave modulation angular frequency, $Y_{0}$ is the base admittance (with dimensions $\Omega^{-1} \mathrm{~s}^{\alpha} \mathrm{cm}^{-2}$ ), and $\alpha$ is and the empirical exponent $(0 \leq \alpha \leq 1)$ which measures the deviation from the ideal capacitive behavior.

One characteristic of the CPE is that when $\alpha \approx 1$, then the base admittance becomes the capacitance $\left(Y_{0}=C\right)$ with the dimension $\mathrm{F} \mathrm{cm}^{-2}$. In Table 1 , the $\alpha_{f}$ parameter associated with the capacitance of film $C_{f}$ suggests a great departure from ideality. This can be attributed to surface roughness and porous nature of the layer with possible presence of corrosion products. However, it is interesting to observe that the increase trend of the film resistance $R_{f}$ is consistent with the assumption that the carboxylate acts plugging the pores, making the film more resistive. On the other hand, the $\alpha$ and 
TABLE 1: Parameters from equivalent circuit analysis of typical impedance data obtained in the blank and solutions containing glutarate with low concentrations ( $1 \mathrm{mM}$ and $5 \mathrm{mM})$.

\begin{tabular}{lccccccc}
\hline Conc $_{\text {inh }} / \mathrm{mM}$ & $R_{s} /\left(\Omega \mathrm{cm}^{2}\right)$ & $Y_{0, f} \times 10^{4} /\left(\Omega^{-1} \mathrm{~s}^{\alpha} \mathrm{cm}^{-2}\right)$ & $\alpha_{f}$ & $R_{f} /\left(\Omega \mathrm{cm}^{2}\right)$ & $Y_{0, \text { int }} \times 10^{4} /\left(\Omega^{-1} \mathrm{~s}^{\alpha} \mathrm{cm}^{-2}\right)$ & $\alpha_{\text {int }}$ & $R_{p} /\left(\mathrm{k} \Omega \mathrm{cm}^{2}\right)$ \\
\hline 0 & 168 & 4.84 & 0.75 & 44 & 12.01 & 0.81 \\
1 & 131 & 7.08 & 0.67 & 160 & 5.52 & 1.64 \\
5 & 120 & 3.66 & 0.74 & 209 & 1.66 & 0.80 & 2.27 \\
\hline
\end{tabular}

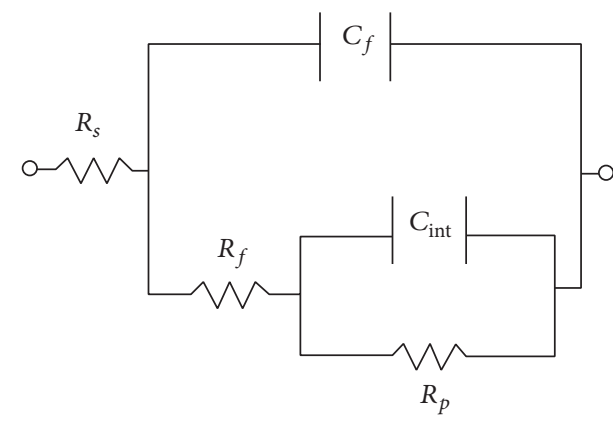

(a)

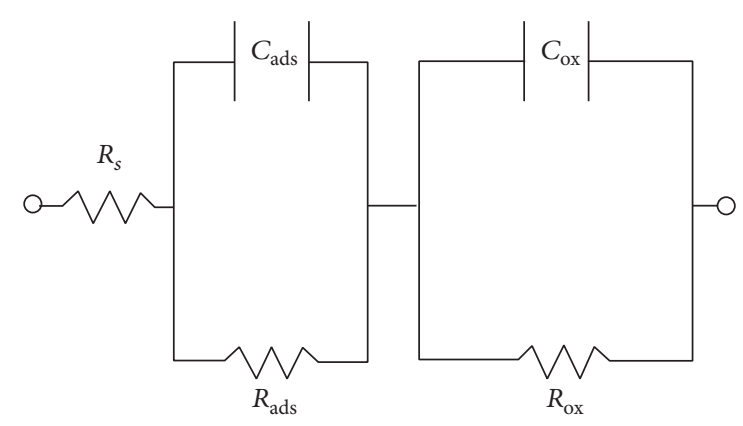

(b)

FIGURE 3: Equivalent circuit models used to fit the experimental results (a) in the blank and solutions with glutarate concentrations $<32 \mathrm{mM}$ and (b) for glutarate concentrations $\geq 32 \mathrm{mM}$.

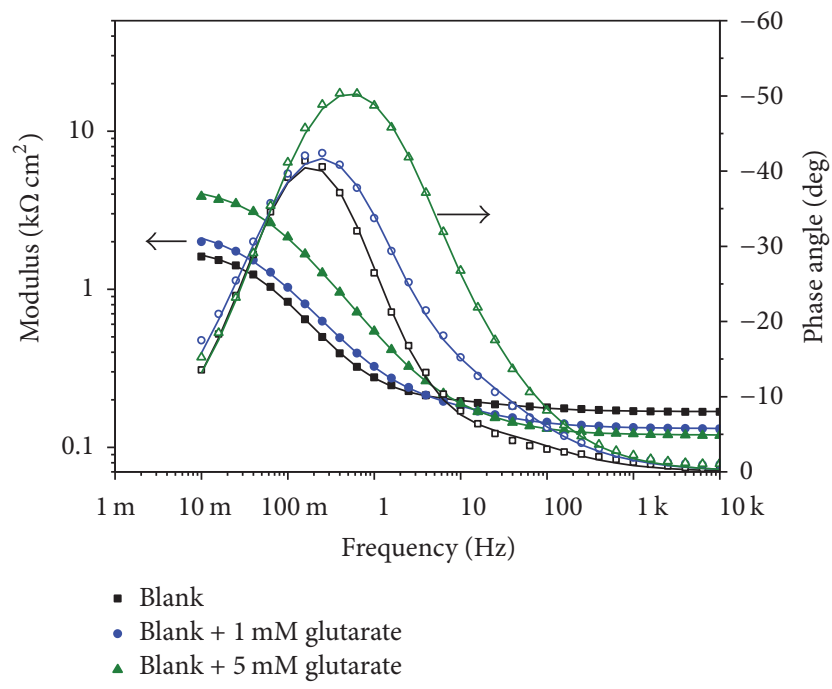

FIGURE 4: Bode plots of carbon steel in aerated $0.02 \mathrm{M} \mathrm{NaCl}$ solution without and with low additions of sodium glutarate $(1 \mathrm{mM}$ and $5 \mathrm{mM})$. The solid lines correspond to fitted curves.

$Y_{0}$ parameters associated with the interfacial capacitance $C_{\text {int }}$ suggest that its estimated values would be higher than the typical value for a double layer capacitance. This is due to the nonhomogeneous nature of the interface at the defect sites and also because it should be related just to a fraction of area of the electrode. Analysis of the parameters in Table 2 shows that both capacitive loops exhibit a nearly ideal behavior and so $Y_{0} \approx C$. This suggests that both the adsorption capacitance and the oxide capacitance would have values in the order of a few hundreds of $\mu \mathrm{F} \mathrm{cm}{ }^{2}$ but still within an acceptable magnitude. The adsorption resistance $R_{\text {ads }}$ clearly

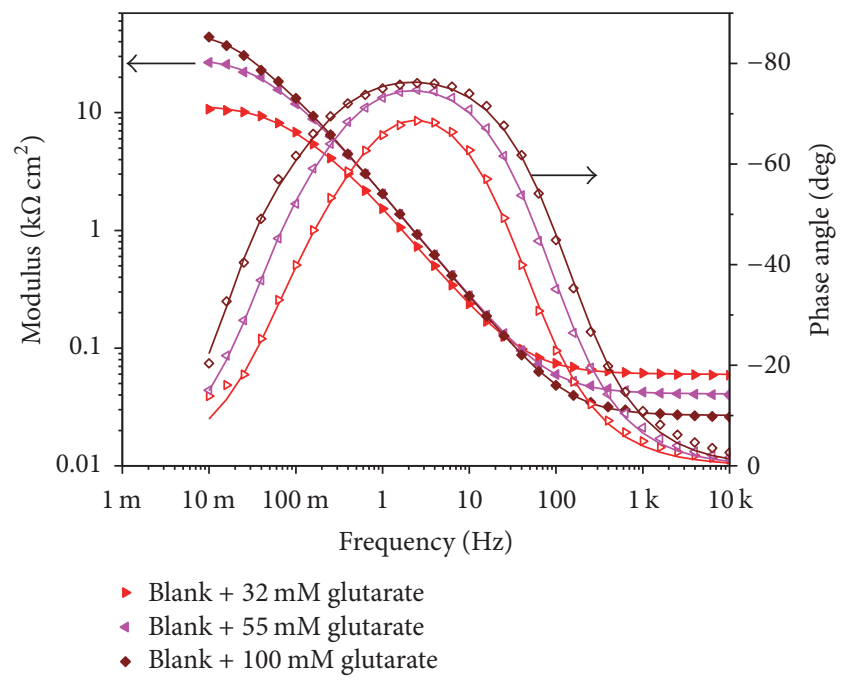

FIgURE 5: Bode plots of carbon steel in aerated $0.02 \mathrm{M} \mathrm{NaCl}$ solution with additions of sodium glutarate $\geq 32 \mathrm{mM}$. The solid lines correspond to fitted curves.

increases with inhibitor concentration, thus giving indication that the adsorption layer becomes more densely packed [14]. Furthermore, the oxide resistance $R_{\text {ox }}$ also increases with inhibitor concentration. Rammelt et al. [13] associated the better protective property of inhibitor mixtures with an increase in $R_{\mathrm{ox}}$, arguing that pore plugging combined with strong adsorption results in an oxide film which becomes increasingly impermeable to the dissolution of ferrous ions. So these results show that although the carbon steel electrode has the same $E_{\text {oc }}$ in solutions with $32 \mathrm{mM}, 55 \mathrm{mM}$, or $100 \mathrm{mM}$ of sodium glutarate, the protectivity increases with inhibitor concentration. 
TABLE 2: Parameters from equivalent circuit analysis of typical impedance data obtained in solutions containing glutarate with concentrations $\geq 32 \mathrm{mM}$.

\begin{tabular}{lccccccc}
\hline Conc $_{\text {inh }} / \mathrm{mM}$ & $R_{s} /\left(\Omega \mathrm{cm}^{2}\right)$ & $Y_{0, \mathrm{ads}} \times 10^{4} /\left(\Omega^{-1} \mathrm{~s}^{\alpha} \mathrm{cm}^{-2}\right)$ & $\alpha_{\text {ads }}$ & $R_{\mathrm{ads}} /\left(\mathrm{k} \Omega \mathrm{cm}^{2}\right)$ & $Y_{0, \mathrm{ox}} \times 10^{4} /\left(\Omega^{-1} \mathrm{~s}^{\alpha} \mathrm{cm}^{-2}\right)$ & $\alpha_{\mathrm{ox}}$ & $R_{\mathrm{ox}} /\left(\mathrm{k} \Omega \mathrm{cm}^{2}\right)$ \\
\hline 32 & 60 & 4.38 & 0.95 & 0.97 & 1.80 & 0.83 \\
55 & 41 & 5.48 & 0.95 & 1.24 & 1.16 & 0.86 \\
100 & 28 & 1.63 & 0.85 & 11.01 & 2.07 & 28.50 \\
\hline
\end{tabular}

TABLE 3: Average inhibition efficiency at $22^{\circ} \mathrm{C}$ estimated from average values of $R_{p}$ and $R_{\mathrm{ox}}$.

\begin{tabular}{lccc}
\hline Conc $_{\text {inh }} / \mathrm{mM}$ & $R_{p} /\left(\mathrm{K} \Omega \mathrm{cm}^{2}\right)$ & $R_{\text {ox }} /\left(\mathrm{k} \Omega \mathrm{cm}^{2}\right)$ & $\left(\eta^{\text {ac }}\right)_{\text {avg }}$ \\
\hline 0 & $1.52 \pm 0.21$ & & \\
1 & $2.29 \pm 0.31$ & & 33.4 \\
5 & $4.24 \pm 0.17$ & & 64.1 \\
32 & & $12.13 \pm 2.3$ & 87.4 \\
55 & & $24.60 \pm 3.9$ & 93.8 \\
100 & & $35.70 \pm 2.1$ & 95.7 \\
\hline
\end{tabular}

Since the Stern-Geary equation is a relationship between the corrosion current density $i_{\text {corr }}$ and the polarization resistance $R_{p}$, the inhibition efficiency $\eta$ can be evaluated from the $R_{p}$ values in Table 1 according to the formula $\eta^{\text {ac }}=$ $\left(1-R_{p}^{B} / R_{p}^{I}\right) \times 100$, where the superscript ac means that it is calculated from impedance parameters and the superscripts $B$ and $I$ refer to blank and inhibited solutions. Furthermore, for the impedance spectra fitted with the equivalent circuit in Figure 3(b), the parameter in Table 2 which is proportional to corrosion resistance is $R_{\mathrm{ox}}$. So, in this case, the formula to calculate efficiency is $\eta^{\text {ac }}=\left(1-R_{p}^{B} / R_{\text {ox }}^{I}\right) \times 100$. In this work, each experiment was repeated at least 3 times to ensure reproducibility. The parameters in Tables 1 and 2 correspond to the typical spectra presented in Figure 2; however, the fittings were carried out for all the experimental data. Therefore, average values of inhibition efficiency at ambient temperature were estimated from the average values of $R_{p}$ and $R_{\text {ox }}$ as presented in Table 3 .

A modest efficiency of $64 \%$ is obtained with $5 \mathrm{mM}$ addition of glutarate (a result in agreement with the work of Hefter at al. [15]). However, a significant improvement in protectivity is achieved by increasing the concentration from $5 \mathrm{mM}$ to $32 \mathrm{mM}$ or even better with $55 \mathrm{mM}$ or $100 \mathrm{mM}$.

Figure 6 shows typical polarization curves obtained after $2 \mathrm{~h}$ immersion of carbon steel at $22^{\circ} \mathrm{C}$ in the $0.02 \mathrm{M} \mathrm{NaCl}$ solution without and with additions of sodium glutarate. Along with the shift in $E_{\text {corr }}$ towards less negative values, there are some important features of the polarization curves: (a) the anodic current density (say $100 \mathrm{mV}$ above $E_{\text {corr }}$ for each polarization curve) decreases with increasing inhibitor concentration, (b) there is also a decrease trend in the corrosion current density $\left(i_{\text {corr }}\right)$, (c) a passivation plateau starts to develop for concentrations $\geq 32 \mathrm{mM}$, and (d) it appears that there is also a modification in the kinetics of oxygen reduction for concentrations $\geq 32 \mathrm{mM}$.

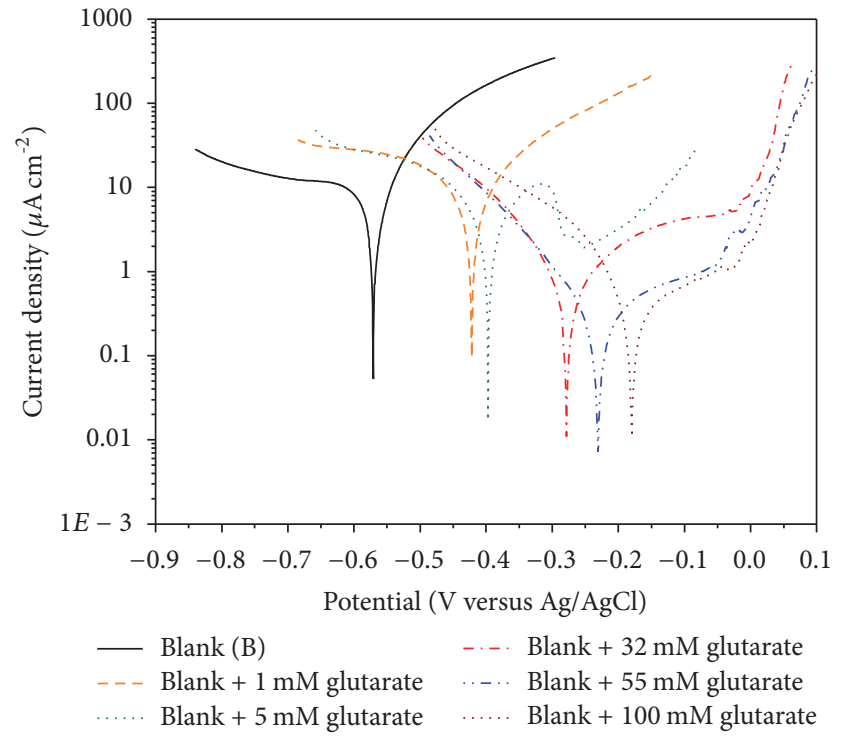

FIGURE 6: Typical polarization curves of carbon steel in $0.02 \mathrm{M} \mathrm{NaCl}$ solution in the absence (blank) and in the presence of different concentrations of sodium glutarate.

TABLE 4: Corrosion current density for carbon steel in $0.02 \mathrm{M} \mathrm{NaCl}$ without and with additions of sodium glutarate. The average values of inhibition efficiency at $22^{\circ} \mathrm{C}$ are also included.

\begin{tabular}{lcc}
\hline Conc $_{\text {inh }} / \mathrm{mM}$ & $i_{\text {corr }} /\left(\mu \mathrm{A} \mathrm{cm}^{-2}\right)$ & $\left(\eta^{\mathrm{dc}}\right)_{\text {avg }}$ \\
\hline 0 & $6.61 \pm 0.39$ & \\
1 & $5.0 \pm 0.40$ & 24.4 \\
5 & $2.34 \pm 0.50$ & 64.6 \\
32 & $0.75 \pm 0.09$ & 88.7 \\
55 & $0.29 \pm 0.07$ & 95.6 \\
100 & $0.26 \pm 0.09$ & 96.1 \\
\hline
\end{tabular}

In Table 3, each experiment was repeated at least 3 times to ensure reproducibility. The same applies for the polarization curves. So, average values of the inhibition efficiency $\eta^{\mathrm{dc}}=\left(1-i_{\text {corr }}^{I} / i_{\text {corr }}^{B}\right) \times 100$ were calculated from the average values of $i_{\text {corr }}$ obtained from the Tafel analysis of polarization curves. The results are presented in Table 4. A reasonable agreement with the values obtained from impedance measurements (Table 3 ) is observed.

3.2. Effect of Temperature. In order to evaluate the stability of protective films on the carbon steel surface as well as 


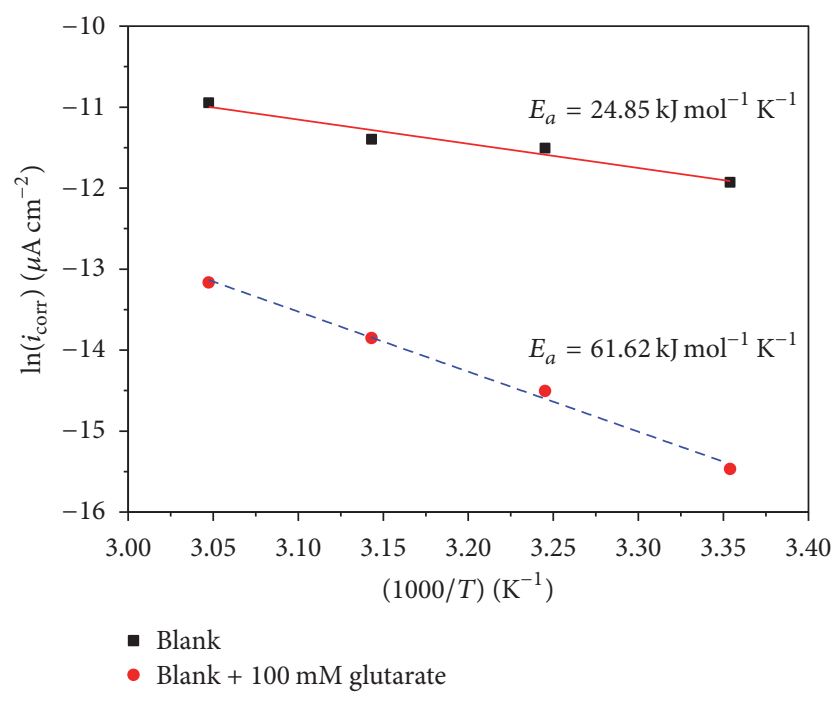

Figure 7: Arrhenius plot of the corrosion of carbon steel in $0.02 \mathrm{M}$ $\mathrm{NaCl}$ solution in the absence and in the presence of $100 \mathrm{mM}$ glutarate.

activation parameters of the corrosion process, potentiodynamic polarization curves were obtained at three more temperatures $\left(35^{\circ} \mathrm{C}, 45^{\circ} \mathrm{C}\right.$, and $\left.55^{\circ} \mathrm{C}\right)$ for the blank and for solutions containing $100 \mathrm{mM}$ of sodium glutarate. The results are presented as an Arrhenius type of plot in Figure 7.

It is evident that as temperature increases, so does the corrosion rate in both the blank and the inhibited solution. For instance, at $55^{\circ} \mathrm{C}$, the values of $i_{\text {corr }}$ are 17.62 and $1.91 \mu \mathrm{A}$ $\mathrm{cm}^{-2}$, respectively, in the blank and inhibited solution. Therefore, the inhibition efficiency decreased from $96.1 \%$ at $22^{\circ} \mathrm{C}$ to $89.1 \%$ at $55^{\circ} \mathrm{C}$. It is expected that raising the temperature leads to higher anodic dissolution of carbon steel and partial desorption of the inhibitor from the metal surface. Nevertheless, these results show that sodium glutarate at a concentration of $100 \mathrm{mM}$ forms a very stable and protective film even at $55^{\circ} \mathrm{C}$.

The activation parameters (activation energy $E_{a}$, activation enthalpy $\Delta H_{a}$, and activation entropy $\Delta S_{a}$ ) were obtained from the Arrhenius equation (1) and the transition state equation (2) for corrosion current density:

$$
\begin{aligned}
& i_{\text {corr }}=A \exp \left(-\frac{E_{a}}{R T}\right), \\
& i_{\text {corr }}=\frac{R T}{N h} \exp \left(\frac{\Delta S_{a}}{R}\right) \exp \left(-\frac{\Delta H_{a}}{R T}\right),
\end{aligned}
$$

where $R$ is the gas constant $\left(8.314 \mathrm{~J} \mathrm{~mol}^{-1} \mathrm{~K}^{-1}\right), T$ is the temperature in $\mathrm{K}, A$ is the preexponential factor, $N$ is Avogadro's number $\left(6.02 \times 10^{23} \mathrm{~mol}^{-1}\right)$, and $h$ is Planck's constant $\left(6.63 \times 10^{-34} \mathrm{~m}^{2} \mathrm{Kg} \mathrm{s}^{-1}\right) . E_{a}$ is obtained from the slope of a $\ln \left(i_{\text {corr }}\right)$ versus $1 / T$ plot; $\Delta H_{a}$ and $\Delta S_{a}$ are obtained from the slope and intercept, respectively, of a $\ln \left(i_{\text {corr }} / T\right)$ versus $1 / T$ plot. The results are presented in Table 5 .

Table 5 shows that $E_{a}$ for the inhibited solution is higher than that for the blank. This suggests that the strong
TABLE 5: Activation parameters for carbon steel in $0.02 \mathrm{M} \mathrm{NaCl}$ solution in the absence and in the presence of $100 \mathrm{mM}$ sodium glutarate.

\begin{tabular}{lccc}
\hline & $E_{a} /\left(\mathrm{kJ} \mathrm{mol}^{-1}\right)$ & $\Delta H_{a} /\left(\mathrm{kJ} \mathrm{mol}^{-1}\right)$ & $\Delta S_{a} /\left(\mathrm{J} \mathrm{mol}^{-1}\right)$ \\
\hline Blank (B) & 24.85 & 22.24 & -269.34 \\
B + 100 mM Glutarate & 61.62 & 59.02 & -175.09 \\
\hline
\end{tabular}

adsorption of glutarate serves to block active sites for metal dissolution on the carbon steel surface, thus creating an energy barrier for charge transfer, leading to a decrease in corrosion rate. The $\Delta H_{a}$ values are positive (i.e., the dissolution process is endothermic) and follow the same trend as the activation energy; in fact, the difference between $E_{a}$ and $\Delta H_{a}$ is $2.6 \mathrm{~kJ} \mathrm{~mol}^{-1}$ which indicates that corrosion kinetics satisfy the following equation from activated complex theory:

$$
E_{a}=\Delta H_{a}+R T
$$

The entropy of activation is negative and large. This implies that the activated complex represents association rather than dissociation step, indicating that a decrease in disorder takes place, going from reactants to the activated complex. Moreover, $\Delta \mathrm{S}_{a}$ values are less negative in inhibited solution than that obtained in the blank. This behavior can be explained as a result of the replacement process of water molecules during adsorption of glutarate on the steel surface [26].

3.3. XPS Analysis of Protective Films. In Figure 8(a), the high resolution $C 1$ s spectrum for native oxide film obtained at an angle of $0^{\circ}$ (normal emission) is presented. Since the carbon steel sample with native oxide film was not immersed in the solution containing the carboxylate, the entire $\mathrm{C}$ $1 s$ signal is attributed to carbonaceous contamination. The deconvolution of this and all the other spectra was carried out with the XPSPEAK software, using a Shirley background correction. In accordance with results reported in the literature for iron oxide layers $[27,28]$, the peak was resolved into three different contributions, characteristic of C-C/C-H, C$\mathrm{O}$, and $\mathrm{O}-\mathrm{C}=\mathrm{O}$ species. The hydrocarbon contribution $(\mathrm{C}-$ $\mathrm{C} / \mathrm{C}-\mathrm{H})$ predominates over the two oxidized carbon species. Angle-resolved XPS measurements are useful for obtaining nondestructive information at different film depths. The depth of the film, from which the photoelectrons escape, decreases with an increase of the takeoff angle. Thus, the bulk of the film is probed at an angle of $0^{\circ}$ (Figure $8(\mathrm{a})$ ) whereas the outer surface is probed at $50^{\circ}$. As shown in Figure 8(b), the $\mathrm{C} 1 \mathrm{~s}$ spectrum for native iron oxide film obtained at a takeoff angle of $50^{\circ}$ is very similar to the one at $0^{\circ}$, with only a difference in the relative contribution of the $\mathrm{C}-\mathrm{O}$ structure which increases in the outer surface.

When organic molecules are adsorbed on the oxidized iron or carbon steel surface, the carbon intensity in the XPS measurement is expected to increase, compared to that observed in a nontreated sample. This is not possible to observe in Figure 8; however, an indirect indication that the intensity of the $C$ 1s signal increases in treated samples is the observation that the signal to noise ratio in Figures 8(c) 


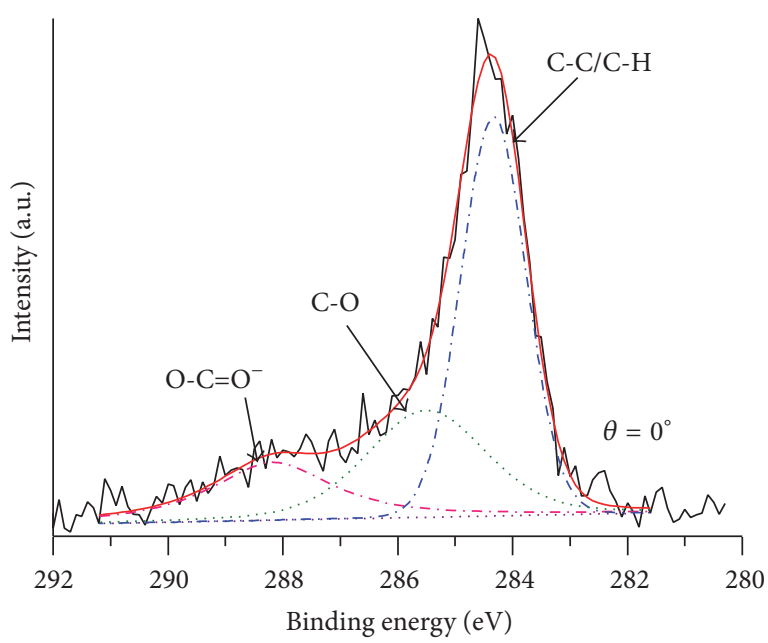

(a)

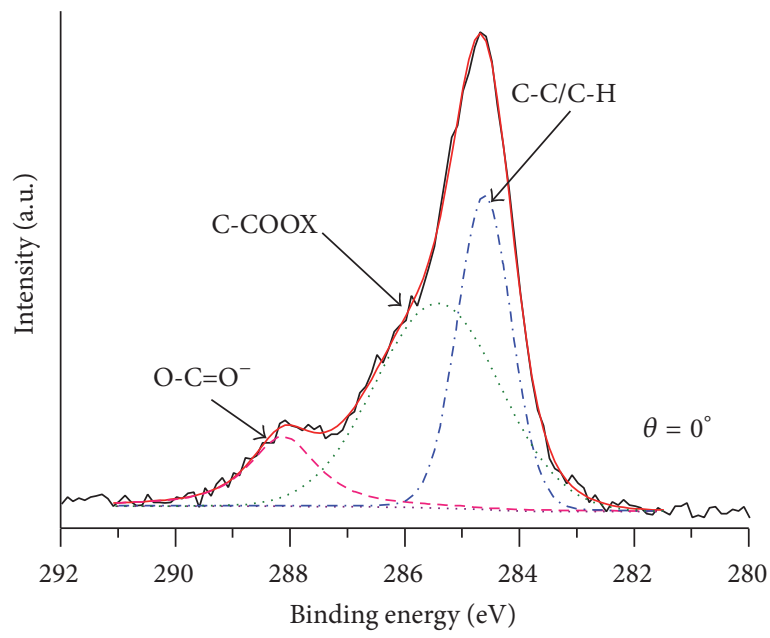

(c)

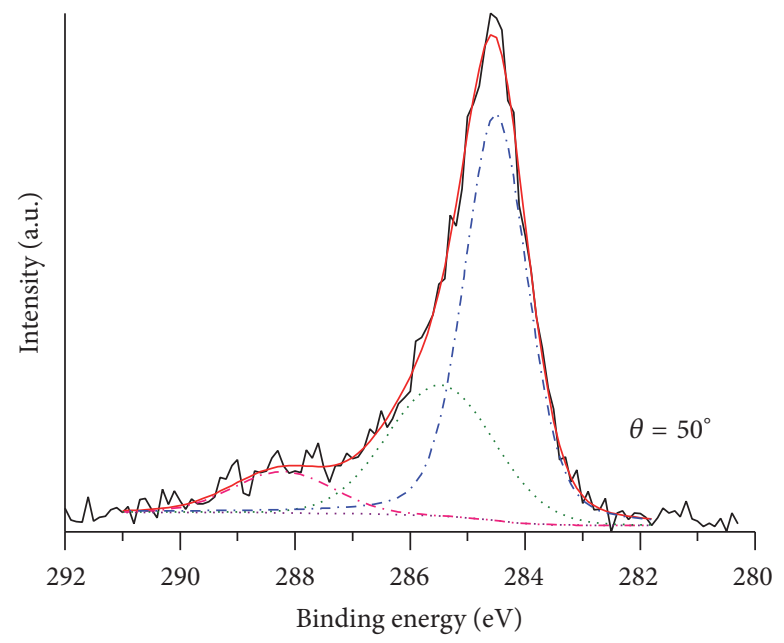

(b)

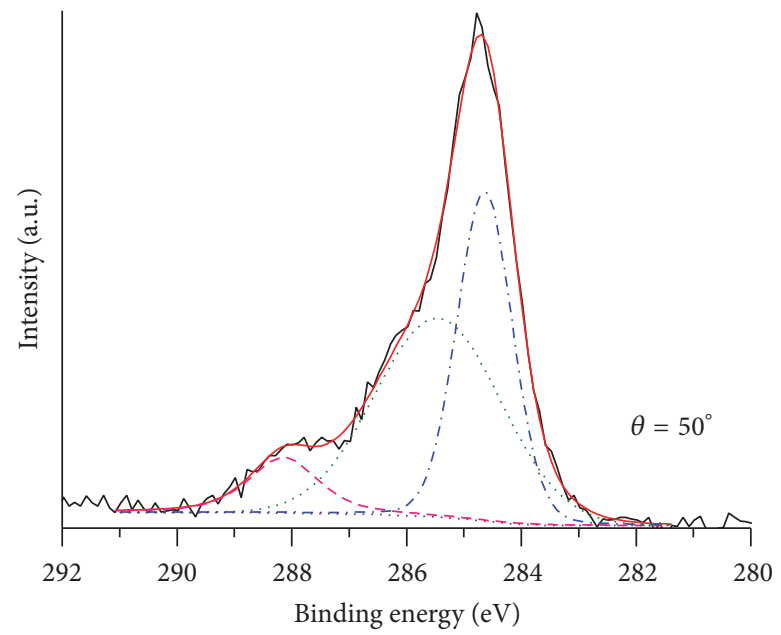

(d)

Figure 8: High resolution C 1s spectra for native oxide film on carbon steel (a, b) and for carbon steel sample after $2 \mathrm{~h}$ immersion in $0.02 \mathrm{M}$ $\mathrm{NaCl}$ solution containing $0.1 \mathrm{M}$ sodium glutarate $(\mathrm{c}, \mathrm{d})$. In each case, results for two different takeoff angles $\left(0^{\circ}\right.$ and $\left.50^{\circ}\right)$ are presented.

and $8(\mathrm{~d})$ (treated) is higher than that in Figures $8(\mathrm{a})$ and 8 (b) (nontreated). A further evidence that the $\mathrm{C} 1 \mathrm{~s}$ signals in Figures 8(c) and 8(d) are due to adsorption of the organic molecule and not to carbonaceous contamination is the fact that the relative contribution of oxidized carbon subpeaks is higher compared to that observed for the native oxide film. In fact, deconvolution of the $\mathrm{C} 1$ s peak in Figure $8(\mathrm{c})$ resulted in 3 subpeaks: the subpeak at a binding energy $(\mathrm{BE}) \sim 284.7 \mathrm{eV}$ can be assigned to the carbon atoms in the saturated chains of the dicarboxylic acid, the one around $285.4 \mathrm{eV}$ to the carbon atom attached to the carboxyl carbon (C-COOX), and the peak at $\mathrm{BE} \sim 288.3 \mathrm{eV}$ to the carboxylate $\left(\mathrm{O}-\mathrm{C}=\mathrm{O}^{-}\right)$, in agreement with results published in related literature [29-31].

A common feature of angle-resolved XPS is that as the takeoff angle increases the intensity of the high resolution spectrum decreases, because the analysis becomes more surface sensitive. So, although not shown, the intensity of the $\mathrm{C}$ 1s spectrum in Figure $8(\mathrm{~d})$ is lower compared to that in
Figure 8(c). It is interesting, however, to observe that the $\mathrm{C}$ 1s signal obtained at $50^{\circ}$ (Figure $8(\mathrm{~d})$ ) has the same shape compared with the one at $0^{\circ}$ (Figure $8(\mathrm{c})$ ) and also that the fitting process leads to the same subpeaks. According to Taheri et al. [31], if undissociated carboxylic acid group (C$\mathrm{COOH}$ ) was present in the surface, it would have a subpeak at a $\mathrm{BE}$ of $\sim 289.1 \mathrm{eV}$. We did not detect such subpeak in the region more near to the surface (Figure $8(\mathrm{~d})$ ); so it appears that both carboxylic acid groups are deprotonated and the $\mathrm{O}-\mathrm{C}=\mathrm{O}^{-}$subpeak gives evidence of the formation of coordinatively bonded carboxylate species at both ends.

As discussed above, the electrochemical measurements give evidence of chemical passivation of the carbon steel and the analysis of the impedance spectra in solutions with glutarate concentration higher than $32 \mathrm{mM}$ suggests that carboxylates are adsorbed on the oxide-covered surface. In other words, the carboxylate ion is expected to be strongly chemisorbed on the passive oxide film. Several 


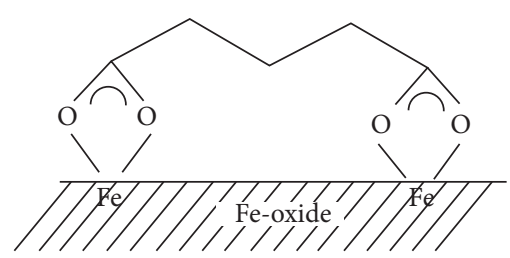

(a)

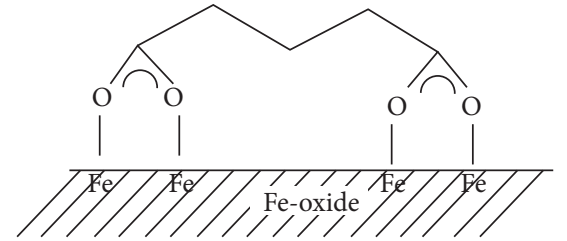

(b)

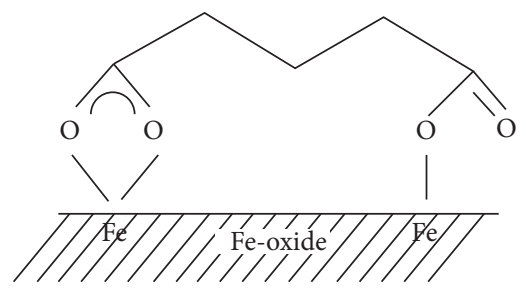

(c)

FIGURE 9: Schematic representation of possible modes of binding of glutarate with the passive film: (a) bidentate chelating at both ends, (b) bidentate bridging at both ends, and (c) bidentate chelating-monodentate.

experimental and theoretical studies on the adsorption of aliphatic mono- and dicarboxylic acids on metal oxide surfaces have been reported in the literature [32-36]. It is commonly acknowledged that chemisorption may occur in different modes, including monodentate, bridge bidentate, and chelating bidentate adsorbed structures. Rajendran et al. [37] reported that adipic acid adsorbs to iron oxide on carbon steel surface in a tetradentate manner. Figure 9 shows three possible modes of binding of glutarate to the passive film in this study. A detailed infrared study will be carried out in a future work to elucidate the actual binding mode.

Figure 10 (a) shows the high resolution Fe $2 \mathrm{p}_{3 / 2}$ spectrum obtained at a takeoff angle of $0^{\circ}$ for the native oxide film. Deconvolution of this spectrum suggests that it consists of 3 subpeaks, corresponding to metallic iron at $\mathrm{BE} \sim 706.3 \mathrm{eV}$, a broad subpeak at $\sim 709.8 \mathrm{eV}$ due to $\mathrm{Fe}^{2+}$ surface species, and a small subpeak at $\mathrm{BE} \sim 710.7 \mathrm{eV}$ ascribed to ferric surface oxidation product $\mathrm{Fe}^{3+}$, in good agreement with results published previously for iron oxides and oxyhydroxides [38-40]. The corresponding $\mathrm{O}$ 1s signal is presented in Figure 10(b). Deconvolution of this spectrum shows that the main contributions are from oxygen in the form of oxide $\left(\mathrm{O}^{2-}\right)$ and hydrous iron oxides $\left(\mathrm{OH}^{-}\right)$. A third subpeak appears at $\mathrm{BE} \sim 532.7 \mathrm{eV}$ which can be ascribed to adsorbed water and oxidized carbon from carbonaceous contamination [27, 28, 31]. As pointed out by Temesghen and Sherwood [38], the use of XPS for the identification of different types of oxidized iron species is complicated because the core Fe2p region shows little difference between different iron compounds. Considering the results of deconvolution of spectra in Figures 10(a) and 10(b), it can be proposed that the native oxide film is composed of a hydrous iron oxide $\mathrm{FeOOH}$ (difficult to distinguish which one) and $\mathrm{Fe}(\mathrm{OH})_{2}$, with possibly a small amount of $\mathrm{Fe}_{3} \mathrm{O}_{4}$. The $\mathrm{Fe} 2 \mathrm{p}_{3 / 2}$ and $\mathrm{O}$ 1s spectra obtained at a takeoff angle of $50^{\circ}$ are presented in Figures 10(c) and 10(d). Deconvolution of these spectra leads to the same subpeaks observed at a takeoff angle of $0^{\circ}$, but with differences in the relative contribution of each subpeak. For the Fe $2 \mathrm{p}_{3 / 2}$ signal, the intensity of the subpeak corresponding to $\mathrm{Fe}^{0}$ decreases since at this angle the outer part of the film is being probed. Figure 10(d) shows that in comparison to Figure 10(b) the contribution of $\mathrm{OH}^{-}$and $\mathrm{H}_{2} \mathrm{O} / \mathrm{C}-\mathrm{O}$ increases. This behavior is consistent with the common observation that the outermost portion of the oxide film is more hydrated [41, 42].

Figure 11(a) shows the high resolution Fe $2 \mathrm{p}_{3 / 2}$ spectrum obtained at a takeoff angle of $0^{\circ}$ for the carbon steel sample that was immersed in the solution containing $0.1 \mathrm{M} \mathrm{Na}$ glutarate. It was also resolved into three subpeaks corresponding to $\mathrm{Fe}^{0}, \mathrm{Fe}^{2+}$, and $\mathrm{Fe}^{3+}$. The presence of the metallic iron subpeak suggests that the passive film is very thin (with thickness in the order of the maximum escape depth of photoelectrons). Noteworthily, the subpeak corresponding to ferric species exhibits a greater contribution compared to the one observed in the native oxide film (Figure 10(a)). Deconvolution of the $\mathrm{O}$ 1s peak (also obtained at a takeoff angle of $0^{\circ}$ ) shows (Figure 11(b)) that it consists of 3 subpeaks. Apart from that, corresponding to oxygen in the form of oxide $\left(\mathrm{O}^{2-}\right)$ and of hydrous iron oxides $\left(\mathrm{OH}^{-}\right)$, a third subpeak at $\mathrm{BE} \sim 532.7 \mathrm{eV}$ was observed, due to oxygen in the carboxylate ion and to adsorbed water. The dominant chemical state is that of $\mathrm{O}^{2-}$; this observation, along with the important contribution of $\mathrm{Fe}^{3+}$ in the $\mathrm{Fe} 2 \mathrm{p}_{3 / 2}$ spectrum, confirms that the passive film developed on the carbon steel surface in the presence of $0.1 \mathrm{M} \mathrm{Na}$-glutarate is very protective. The passive film itself might be a bilayer, with an outer region of $\mathrm{FeOOH}$ and and inner oxide region $\left(\mathrm{Fe}_{3} \mathrm{O}_{4}\right.$ or possibly $\mathrm{Fe}_{2} \mathrm{O}_{3}$ ). Furthermore, as discussed above, this passive film is covered by an organic layer (chemisorbed carboxylate). This structure is consistent with the schematic representations in Figure 9. Deconvolution of the Fe $2 \mathrm{p}_{3 / 2}$ and $\mathrm{O}$ 1s spectra obtained at a takeoff angle of $50^{\circ}$ (Figures 


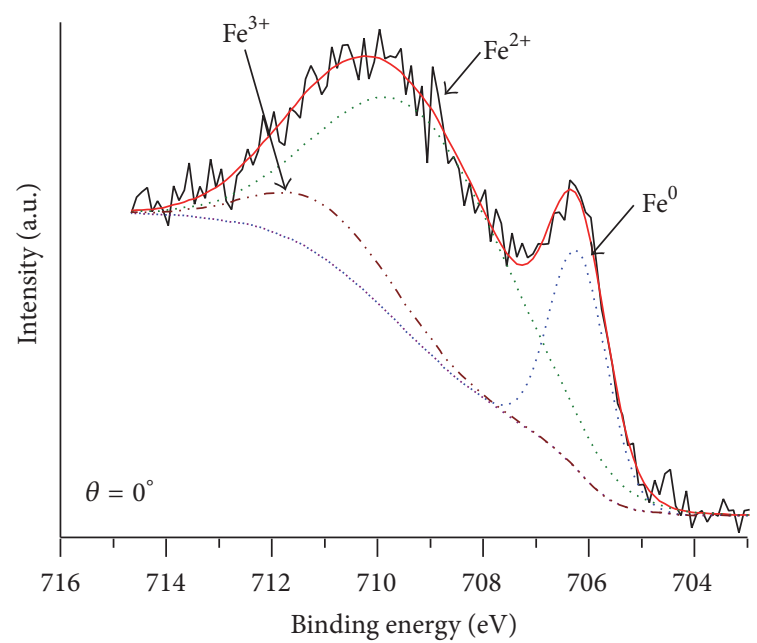

(a)

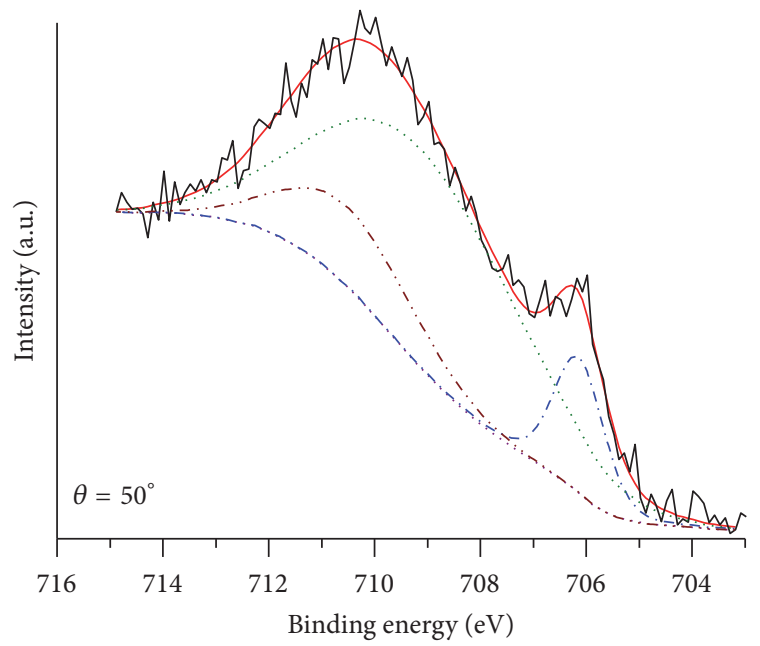

(c)

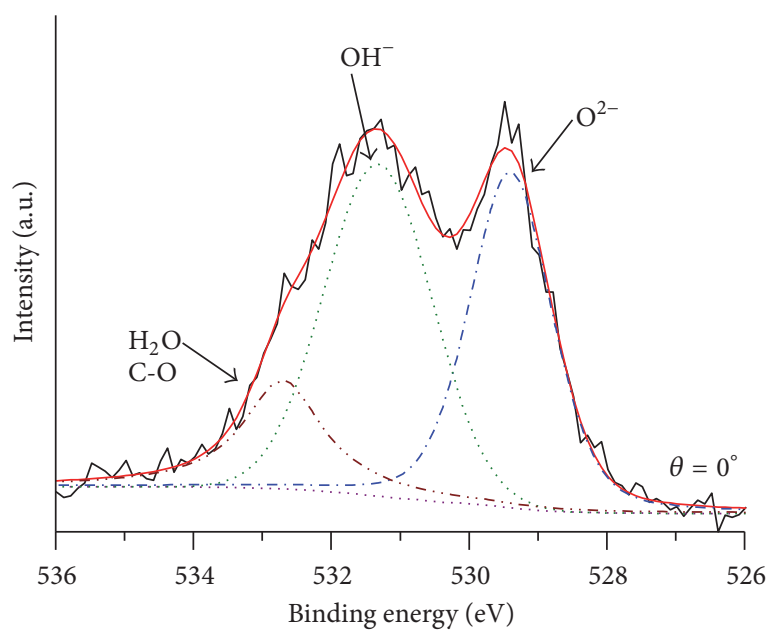

(b)

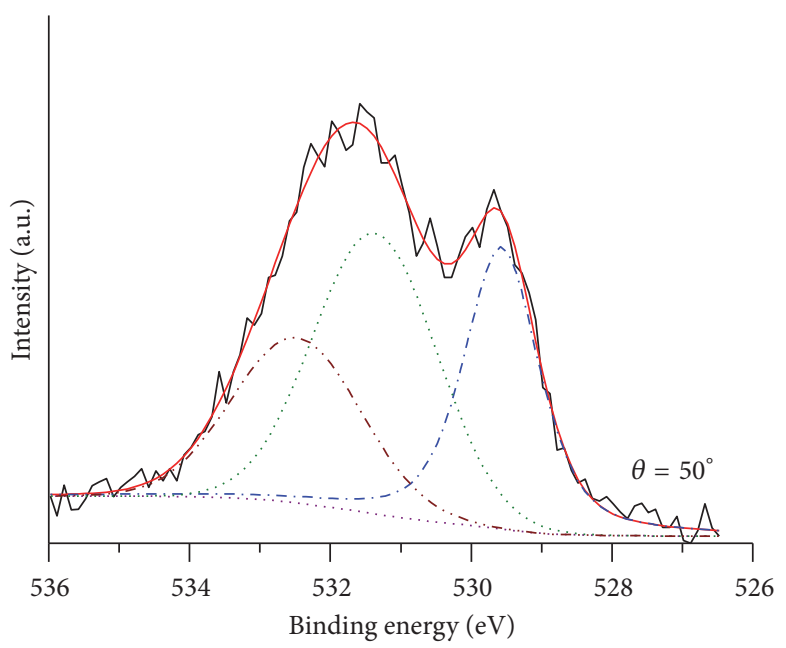

(d)

FIgURE 10: High resolution Fe $2 \mathrm{p}_{3 / 2}$ and $\mathrm{O}$ 1s spectra for native oxide film, obtained at a takeoff angle of $0^{\circ}$ (a, b) and of $50^{\circ}$ (c, d).

11(c) and 11(d)) shows that optimum fitting leads to the same subpeaks observed at a takeoff angle of $0^{\circ}$. However, the following differences in the relative contribution of subpeaks are observed: the $\mathrm{Fe}^{0}$ subpeak in the $\mathrm{Fe} 2 \mathrm{p}_{3 / 2}$ spectrum decreases and the $\mathrm{OH}^{-}$subpeak in the $\mathrm{O}$ 1s spectrum increases. These observations are consistent with the fact that at a takeoff angle of $50^{\circ}$ the outermost region of the film is being probed. This region is more hydrated and the response is mainly from the oxyhydroxide/oxide, with little contribution from the substrate.

\section{Conclusions}

Sodium glutarate showed a poor inhibitive action for corrosion of carbon steel in a $0.02 \mathrm{M} \mathrm{NaCl}$ solution when used in concentrations of $1 \mathrm{mM}$ and $5 \mathrm{mM}$. However, open circuit potential and polarization curve measurements give evidence that full chemical passivation is accomplished for concentrations of $32 \mathrm{mM}$ or higher; a significant improvement in protectivity is achieved. Investigation of the effect of temperature showed that increasing the temperature from $22^{\circ} \mathrm{C}$ to $55^{\circ} \mathrm{C}$ decreases the inhibition efficiency from $96 \%$ to $89 \%$, indicating good stability of the protective film in this temperature range. Analysis of the impedance spectra for the high concentrations of glutarate was consistent with the inhibition mechanism which assumes that the carboxylates support the passivation of carbon steel in aerated solutions by plugging the defect sites and that the passivation process is enhanced by adsorption of the carboxylates on the oxidecovered surface. Such mechanism was confirmed by the XPS analysis.

\section{Competing Interests}

The authors declare that there is no conflict of interests regarding the publication of this paper. 


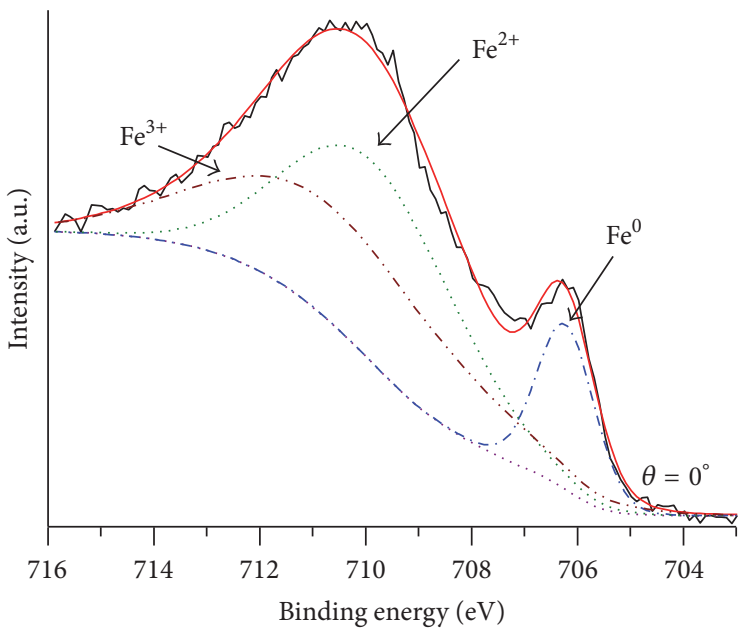

(a)

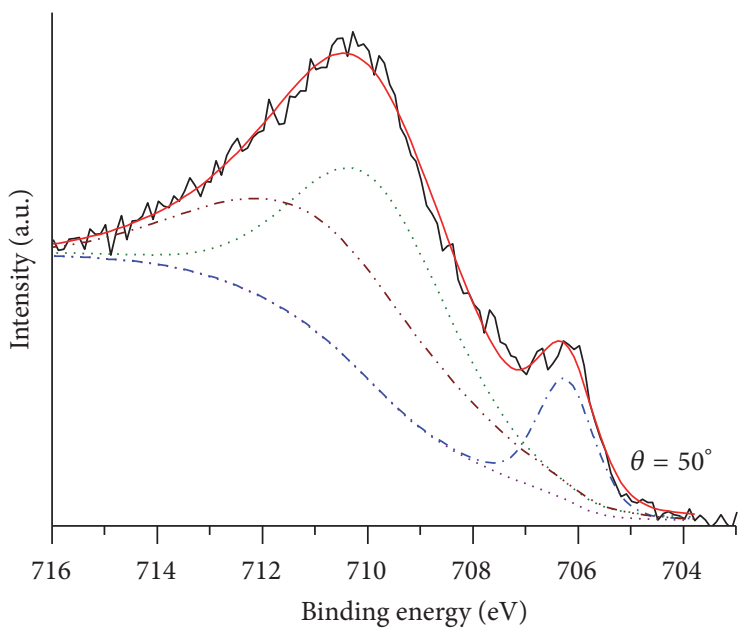

(c)

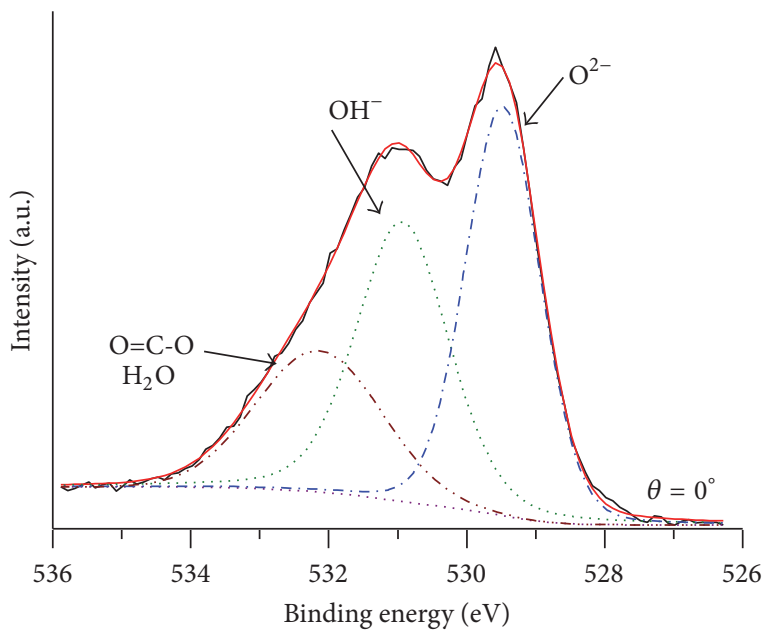

(b)

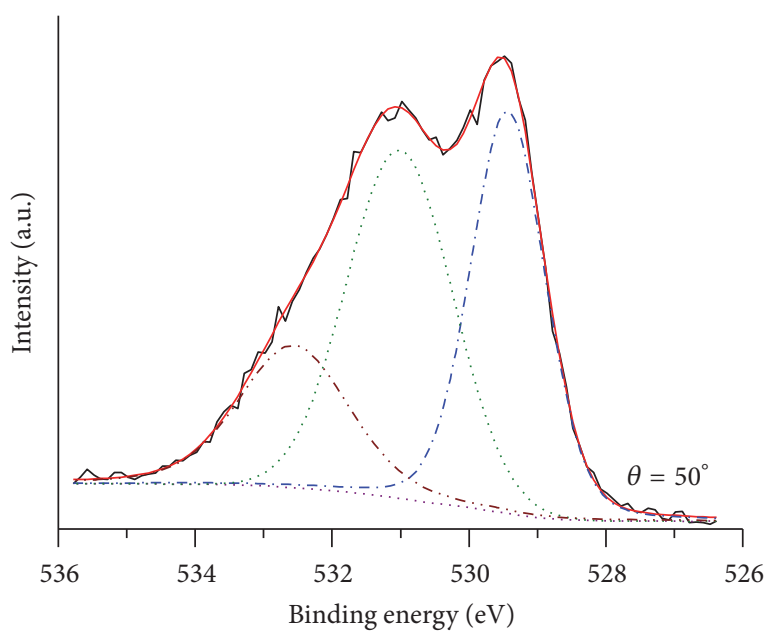

(d)

Figure 11: High resolution $\mathrm{Fe} 2 \mathrm{p}_{3 / 2}$ and $\mathrm{O} 1 \mathrm{~s}$ spectra for carbon steel after $2 \mathrm{~h}$ immersion in $0.02 \mathrm{M} \mathrm{NaCl}$ containing $0.1 \mathrm{M}$ Na-glutarate; spectra obtained at a takeoff angle of $0^{\circ}(a, b)$ and of $50^{\circ}(c, d)$.

\section{Acknowledgments}

The authors are grateful to Ms. Marbella Echeverría for technical assistance in the corrosion/electrochemistry laboratory and to Mr. W. Cauich for technical assistance with the XPS measurements. Finally, the first author is thankful to Conacyt-México for providing a scholarship for his doctoral studies.

\section{References}

[1] R. W. Revie and H. H. Uhlig, Corrosion and Corrosion Control, An Introduction to Corrosion Science and Engineeering, John Wiley Sons, New Jersey, USA, 4th edition, 2008.

[2] S. Turgoose, "Mechanism of corrosion inhibition in neutral environments," in Chemical Inhibitors for Corrosion Control, B. G. Clubley, Ed., Royal Society of Chemistry, Cambridge, UK, 1990.
[3] A. D. Mercer, "Some views on the corrosion mechanisms of inhibitors in neutral solutions," Materials Performance, vol. 29, no. 6, pp. 45-53, 1990.

[4] Y. I. Kuznetsov, "Physicochemical aspects of metal corrosion inhibition in aqueous solutions," Russian Chemical Reviews, vol. 73, no. 1, pp. 75-87, 2004.

[5] B. Sanyal, "Organic compounds as corrosion inhibitors in different environments-a review," Progress in Organic Coatings, vol. 9, no. 2, pp. 165-236, 1981.

[6] J.-W. Song, E.-Y. Jeon, D.-H. Song et al., "Multistep enzymatic synthesis of long-chain $\alpha, \omega$-dicarboxylic and $\omega$-hydroxycarboxylic acids from renewable fatty acids and plant oils," Angewandte Chemie International Edition, vol. 52, no. 9, pp. 2534-2537, 2013.

[7] M. Alam, D. Akram, E. Sharmin, F. Zafar, and S. Ahmad, "Vegetable oil based eco-friendly coating materials: a review article," Arabian Journal of Chemistry, vol. 7, no. 4, pp. 469-479, 2014. 
[8] D. M. Brasher and A. D. Mercer, "Comparative study of factors influencing the action of corrosion inhibitors for mild steel in neutral solution: I. Sodium benzoate," British Corrosion Journal, vol. 3, no. 3, pp. 120-129, 1968.

[9] C. L. Pace and J. E. O. Mayne, "The anomalous effect of concentrationon inhibition of the corrosion of iron by solutions of sodium benzoate," Corrosion Science, vol. 12, no. 8, pp. 679681, 1972.

[10] U. Rammelt, S. Koehler, and G. Reinhard, "Synergistic effect of benzoate and benzotriazole on passivation of mild steel," Corrosion Science, vol. 50, no. 6, pp. 1659-1663, 2008.

[11] G. Mrowczynski and Z. Szklarska-Smialowska, "Electrochemical and eclipsometric study of iron corrosion inhibition in sodium sulphate solutions containing aliphatic acids," Journal of Applied Electrochemistry, vol. 9, no. 2, pp. 201-207, 1979.

[12] G. Reinhard, M. Radtke, and U. Rammelt, "On the role of the salts of weak acids in the chemical passivation of iron and steel in aqueous solutions," Corrosion Science, vol. 33, no. 2, pp. 307313, 1992.

[13] U. Rammelt, S. Köhler, and G. Reinhard, "EIS characterization of the inhibition of mild steel corrosion with carboxylates in neutral aqueous solution," Electrochimica Acta, vol. 53, no. 23, pp. 6968-6972, 2008.

[14] U. Rammelt, S. Koehler, and G. Reinhard, "Electrochemical characterisation of the ability of dicarboxylic acid salts to the corrosion inhibition of mild steel in aqueous solutions," Corrosion Science, vol. 53, no. 11, pp. 3515-3520, 2011.

[15] G. T. Hefter, N. A. North, and S. H. Tan, "Organic corrosion inhibitors in neutral solutions; part 1-inhibition of steel, copper, and aluminum by straight chain carboxylates," Corrosion, vol. 53, no. 8, pp. 657-667, 1997.

[16] D. Lahem, M. Poelman, F. Atmani, and M.-G. Olivier, "Synergistic improvement of inhibitive activity of dicarboxylates in preventing mild steel corrosion in neutral aqueous solution," Corrosion Engineering Science and Technology, vol. 47, no. 6, pp. 463-471, 2012.

[17] G. R. H. Florence, A. N. Anthony, J. W. Sahayaraj, A. J. Amalraj, and S. Rajendran, "Corrosion inhibition of carbon steel by adipic acid- $\mathrm{Zn}^{2+}$ system," Indian Journal of Chemical Technology, vol. 12, no. 4, pp. 472-476, 2005.

[18] M. Manovannan and S. Rajendran, "Corrosion inhibition of carbon steel by succinic acid- $\mathrm{Zn}^{2+}$ system," Research Journal of Chemical Sciences, vol. 1, no. 8, pp. 42-48, 2011.

[19] D. Gilroy and J. E. O. Mayne, "The breakdown of the air-formed oxide film on iron upon immersion in solutions of $\mathrm{pH}$ 6-13," British Corrosion Journal, vol. 1, no. 3, pp. 102-106, 1965.

[20] H. Konno, M. Kawai, and M. Nagayama, "The mechanism of spontaneous dissolution of the air-formed oxide film on iron in a deaerated neutral phosphate solution," Surface Technology, vol. 24, no. 3, pp. 259-271, 1985.

[21] G. H. Cartledge, "The comparative roles of oxygen and inhibitors in the passivation of iron. I. Non-oxidizing inhibitors," Journal of Physical Chemistry, vol. 64, no. 12, pp. 1877-1882, 1960.

[22] D. M. Brasher, "Stability of the oxide film on metals in relation to inhibition of corrosion. II. Dual role of the anion in the inhibition of the corrosion of mild steel," British Corrosion Journal, vol. 4, no. 3, pp. 122-128, 2013.

[23] E. McCafferty, Introduction to Corrosion Science, Springer Science+Business Media, New York, NY, USA, 2010.
[24] F. Mansfeld, M. W. Kendig, and W. J. Lorenz, "Corrosion inhibition in neutral, aerated media," Journal of the Electrochemical Society, vol. 132, no. 2, pp. 290-296, 1985.

[25] K. Jüuttner, W. J. Lorenz, W. Paatsch, M. Kendig, and F. Mansfeld, "Bedeutung der dynamischen systemanalyse für korrosionsuntersuchungen in forschung und praxis," Materials and Corrosion, vol. 36, no. 3, pp. 120-130, 1985.

[26] O. Dagdag, M. El Gouri, M. Galai, M. Ebn Touhami, A. Essamri, and A. Elharfi, "Effect of temperature on the corrosion inhibition of carbon steel in $3 \% \mathrm{NaCl}$ by hexa propylene glycol cyclotriphosphazene," Der Pharma Chemica, vol. 7, no. 4, pp. 284-293, 2015.

[27] G. Bhargava, I. Gouzman, C. M. Chun, T. A. Ramanarayanan, and S. L. Bernasek, "Characterization of the "native" surface thin film on pure polycrystalline iron: a high resolution XPS and TEM study," Applied Surface Science, vol. 253, no. 9, pp. 43224329, 2007.

[28] J. Wielant, T. Hauffman, O. Blajiev, R. Hausbrand, and H. Terryn, "Influence of the iron oxide acid-base properties on the chemisorption of model epoxy compounds studied by XPS," Journal of Physical Chemistry C, vol. 111, no. 35, pp. 13177-13184, 2007.

[29] E. Johansson and L. Nyborg, "XPS study of carboxylic acid layers on oxidized metals with reference to particulate materials," Surface and Interface Analysis, vol. 35, no. 4, pp. 375-381, 2003.

[30] M. De Keersmaecker, O. Van den Berg, K. Verbeken, D. Depla, and A. Adriaens, "Hydrogenated dimer acid as a corrosion inhibitor for lead metal substrates in acetic acid," Journal of the Electrochemical Society, vol. 162, no. 4, pp. C167-C179, 2015.

[31] P. Taheri, J. Wielant, T. Hauffman et al., "A comparison of the interfacial bonding properties of carboxylic acid functional groups on zinc and iron substrates," Electrochimica Acta, vol. 56, no. 4, pp. 1904-1911, 2011.

[32] A. D. Buckland, C. H. Rochester, and S. A. Topham, "Infrared study of the adsorption of carboxylic acids on haematite and goethite immersed in carbon tetrachloride," Journal of the Chemical Society, Faraday Transactions 1: Physical Chemistry in Condensed Phases, vol. 76, pp. 302-313, 1980.

[33] O. W. Duckworth and S. T. Martin, "Surface complexation and dissolution of hematite by $\mathrm{C}_{1}-\mathrm{C}_{6}$ dicarboxylic acids at $\mathrm{pH}=5.0$," Geochimica et Cosmochimica Acta, vol. 65, no. 23, pp. 42894301, 2001.

[34] S. J. Hug and D. Bahnemann, "Infrared spectra of oxalate, malonate and succinate adsorbed on the aqueous surface of rutile, anatase and lepidocrocite measured with in situ ATRFTIR," Journal of Electron Spectroscopy and Related Phenomena, vol. 150, no. 2-3, pp. 208-219, 2006.

[35] K. D. Dobson and A. J. McQuillan, "In situ infrared spectroscopic analysis of the adsorption of aliphatic carboxylic acids to $\mathrm{TiO}_{2}, \mathrm{ZrO}_{2}, \mathrm{Al}_{2} \mathrm{O}_{3}$, and $\mathrm{Ta}_{2} \mathrm{O}_{5}$ from aqueous solutions," Spectrochimica Acta A, vol. 55, no. 7-8, pp. 1395-1405, 1999.

[36] Y. S. Hwang and J. J. Lenhart, "Adsorption of C4-dicarboxylic acids at the hematite/water interface," Langmuir, vol. 24, no. 24, pp. 13934-13943, 2008.

[37] S. Rajendran, V. Shribharathy, A. Krishnaveni et al., "Corrosion inhibitive property of self-assembled Nano Films formed by Adipic Acid molecules on carbon steel surface," Elixir Thin Film Technology, vol. 50, pp. 10509-10513, 2012.

[38] W. Temesghen and P. M. A. Sherwood, "Analytical utility of valence band X-ray photoelectron spectroscopy of iron and its oxides, with spectral interpretation by cluster and band 
structure calculations," Analytical and Bioanalytical Chemistry, vol. 373, no. 7, pp. 601-608, 2002.

[39] A. P. Grosvenor, B. A. Kobe, M. C. Biesinger, and N. S. McIntyre, "Investigation of multiplet splitting of Fe 2p XPS spectra and bonding in iron compounds," Surface and Interface Analysis, vol. 36, no. 12, pp. 1564-1574, 2004.

[40] G. M. Atenas, E. Mielczarski, and J. A. Mielczarski, "Composition and structure of iron oxidation surface layers produced in weak acidic solutions," Journal of Colloid and Interface Science, vol. 289, no. 1, pp. 157-170, 2005.

[41] G. W. Simmons and B. C. Beard, "Characterization of acid-base properties of the hydrated oxides on iron and titanium metal surfaces," The Journal of Physical Chemistry, vol. 91, no. 5, pp. 1143-1148, 1987.

[42] E. McCafferty and J. P. Wightman, "Determination of the concentration of surface hydroxyl groups on metal oxide films by a quantitative XPS method," Surface and Interface Analysis, vol. 26, no. 8, pp. 549-564, 1998. 

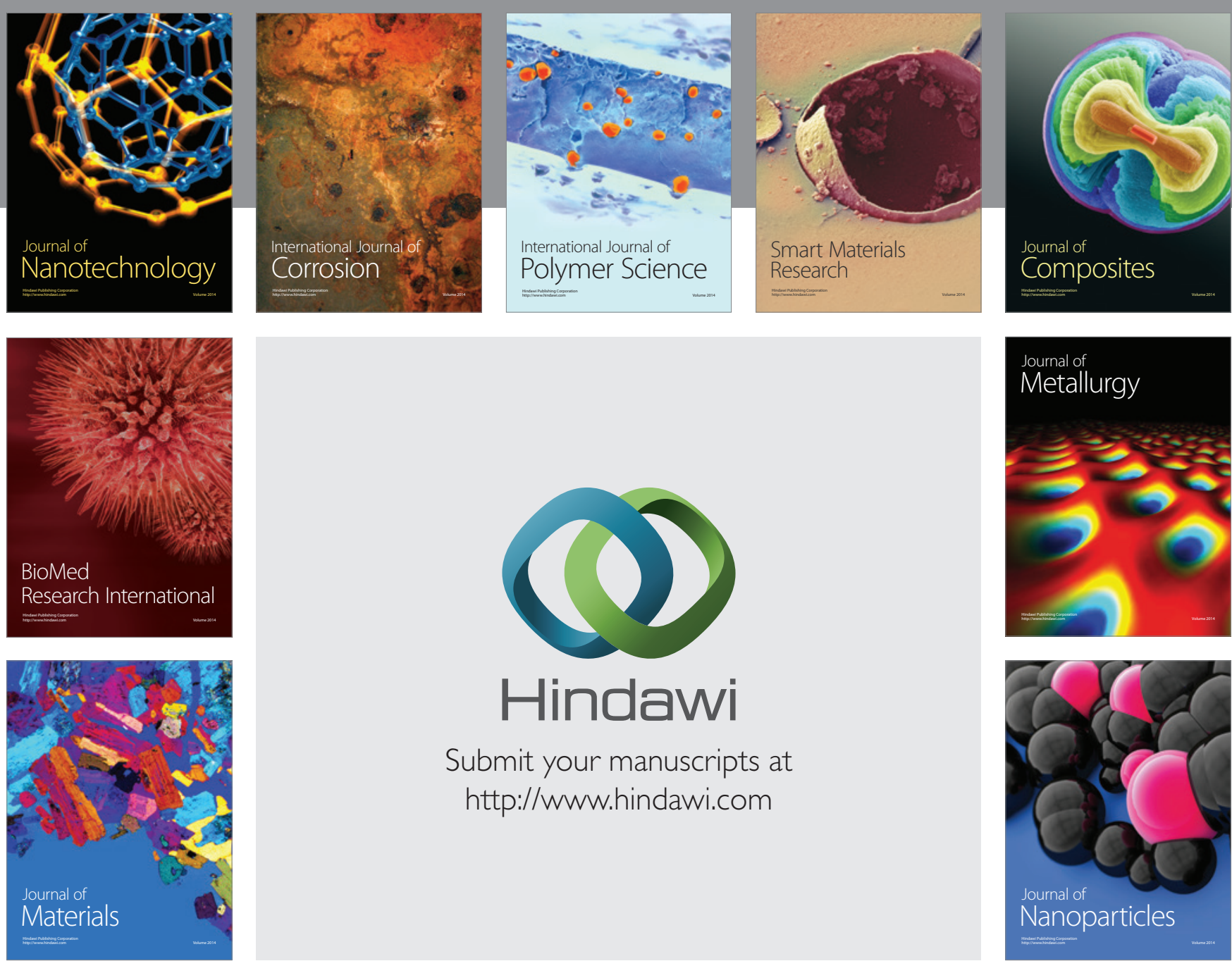

\section{Hindawi}

Submit your manuscripts at

http://www.hindawi.com

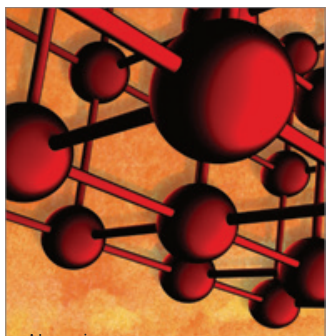

Materials Science and Engineering
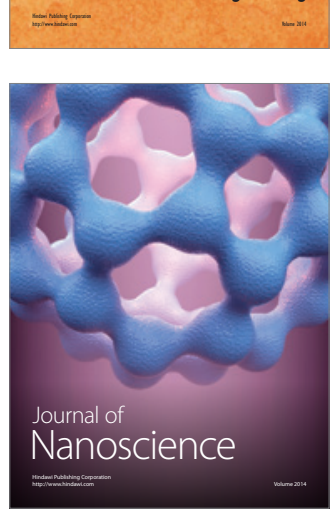
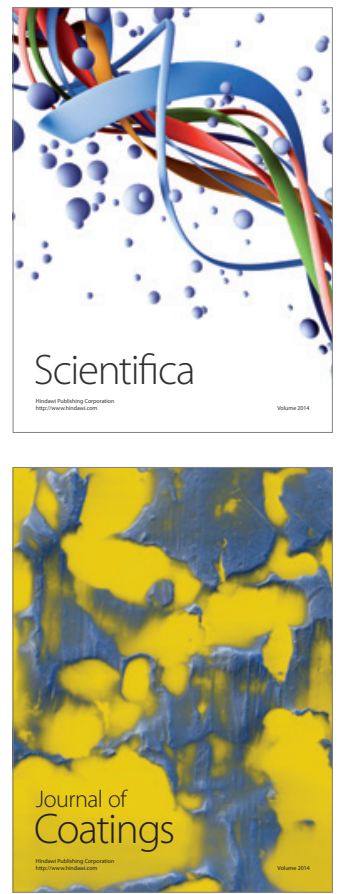
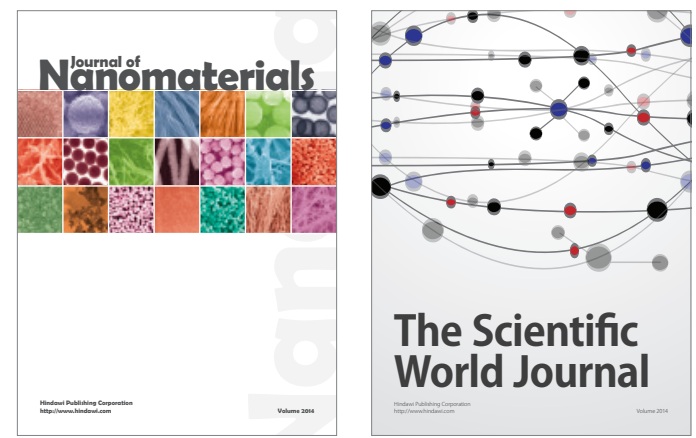

The Scientific World Journal
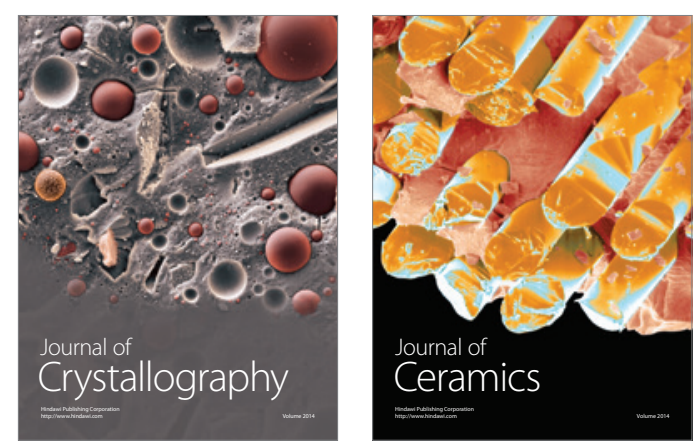
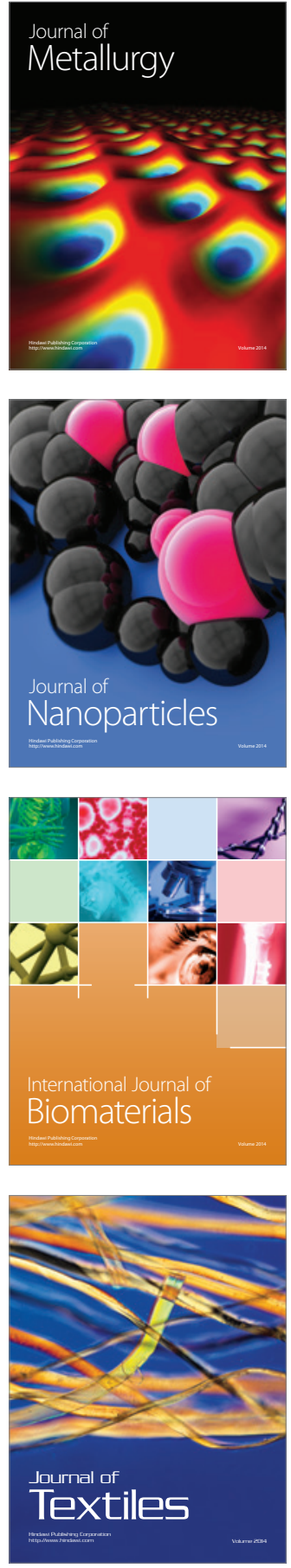